\title{
Ventral tegmental area-basolateral amygdala-nucleus accumbens shell neurocircuitry controls the expression of heroin-conditioned immunomodulation
}

\author{
Jennifer L. Szczytkowski ${ }^{1}$, Rita A. Fuchs, and Donald T. Lysle \\ University of North Carolina at Chapel Hill, Department of Psychology, CB\#3270, Chapel Hill, NC \\ 27599-3270 USA
}

\begin{abstract}
The present investigations sought to determine whether the ventral tegmental area (VTA), basolateral amygdala (BLA), and nucleus accumbens shell (NAC) comprise a circuitry that mediates heroin-induced conditioned immunomodulation. Rats were given conditioning trials in which they received an injection of heroin upon placement into a distinctive environment. Prior to testing, rats received unilateral intra-BLA microinfusion of a $\mathrm{D}_{1}$ antagonist concomitantly with unilateral intra-NAC shell microinfusion of an NMDA antagonist. Disconnection of the VTABLA-NAC circuit impaired the ability of the heroin-paired environment to suppress lipopolysaccharide-induced immune responses, defining for the first time a specific neural circuit involved in conditioned neural-immune interactions.
\end{abstract}

\section{Keywords}

basolateral amygdala, heroin; nucleus accumbens shell; dopamine; glutamate; nitric oxide

\section{Introduction}

Opioid treatment in rats suppresses a number of in vivo immune responses, including the production of nitric oxide, a key component of host defense against bacterial infection (e.g., Fecho et al., 1996a; 1996b; Lysle et al., 1993; Lysle \& How, 2000; Nelson et al., 2000). In addition, opioid drugs also suppress in vivo expression of proinflammatory cytokines (Chao et al 1993; Bencsics et al 1997; Pacifici et al 2000; Clark et al., 2007). Proinflammatory cytokines, such as IL-6 and TNF- $a$, play critical roles in the body's defense against infectious challenge, while also serving to regulate the immune response to these challenges. There is now substantial evidence that these effects of opioid drugs on the immune system are generated via actions within the CNS. For example, intraventricularly administered Nmethylnaltrexone (an opioid antagonist that does not readily cross the blood-brain barrier) dose-dependently antagonizes the immunomodulatory effects of systemic morphine administration, whereas peripheral administration of $\mathrm{N}$-methylnaltrexone is ineffective in blocking morphine's effects (Lysle et al., 1996; Fecho et al., 1996a). Furthermore, microinjection of morphine into the periacqueductal gray results in suppression of NK cell

(C) 2010 Elsevier B.V. All rights reserved.

1jthomson@email.unc.edu Telephone: +1-919-962-4149, Fax: +1-919-962-2537.

Publisher's Disclaimer: This is a PDF file of an unedited manuscript that has been accepted for publication. As a service to our customers we are providing this early version of the manuscript. The manuscript will undergo copyediting, typesetting, and review of the resulting proof before it is published in its final citable form. Please note that during the production process errors may be discovered which could affect the content, and all legal disclaimers that apply to the journal pertain. 
cytotoxicity which can be blocked by peripheral administration of naltrexone, an opioid antagonist (Weber \& Pert, 1989). Remarkably, the suppressive effects of opioids on the immune system can be conditioned to environmental stimuli paired with drug administration (Lysle \& Ijames, 2002) such that the previously heroin-paired environment alone elicits heroin-like changes in immune functioning. Conditioned immune alterations brought about by exposure to drug cues may manifest as an increased susceptibility to opportunistic infections and a decreased ability to combat infectious diseases in recovering drug users. A clear understanding of the neurotransmitters and neural circuitry involved in heroinconditioned immunomodulation is necessary for the development of pharmacotherapeutic interventions that might be employed in susceptible populations before infections lead to irreversible organ damage and other detrimental health consequences.

Recent studies in our laboratory and others have identified key brain structures involved in the mediation of conditioned immunomodulation. For example, several brain structures are critically involved in the expression and acquisition of immune alterations in a conditioned taste aversion model. These include the insular cortex, amygdala and the ventromedial nucleus of the hypothalamus (Chen et al., 2004; Pacheco-Lopez et al., 2005; RamirezAmaya \& Bermudez-Rattoni, 1999; Ramirez-Amaya et al., 1998; Ramirez-Amaya et al., 1996). Our own laboratory recently demonstrated that dopamine neurotransmission in the basolateral amygdala (BLA) and nucleus accumbens shell (NAC) is necessary for heroinconditioned and morphine-conditioned immunomodulation, respectively (Szczytkowski \& Lysle, 2008; Saurer et al., 2009). Specifically, $\mathrm{D}_{1}$ dopaminergic receptor antagonism in these structures inhibits conditioned decreases in the production of proinflammatory mediators in peripheral immune tissues (Szczytkowski \& Lysle, 2010). This implies that the ventral tegmental area (VTA), the primary source of dopamine to the BLA in the rat (Ford et al., 2006), is an element of the neural circuitry mediating heroin-conditioned immune regulation. In addition to dopamine, glutamate input to the NAC is important for conditioned behaviors. For instance, AMPA or NMDA receptor antagonism in the NAC disrupts 7-OHDPAT conditioned place preference (Biondo et al., 2005) and AMPA antagonism in the NAC inhibits cocaine context-induced drug seeking behavior (Xie et al., 2011). Despite these significant findings regarding the contributions of individual brain regions, no attempt has been made to identify functionally significant connections between these brain regions thus to map the neural circuitry responsible for heroin-induced conditioned immunomodulation, specifically, or for conditioned immune alterations, in general. Given the critical role of dopamine in the BLA in conditioned immunomodulation and the existence of glutamatergic BLA afferents to the NAC (Kelley et al, 1982; McDonald, 1991; Wright et al, 1996), we hypothesized that the VTA-BLA-NAC circuitry may control the conditioned effects of heroin on immune measures.

To begin testing this hypothesis, we first evaluated whether ionotropic glutamate receptor antagonism in the NAC shell would block heroin-conditioned suppression of nitric oxide and the proinflammatory cytokines, tumor necrosis factor- $a$ (TNF- $a$ ) and interleukin- 6 (IL-6), in response to a lipopolysaccharide (LPS) immune challenge. Research has shown a role for both NMDA and AMPA/kainate receptors in various drug-conditioned responses (Hotsenpiller et al., 2001; Rodriguez-Borrero et al., 2006; Backstrom \& Hyytia, 2007). Therefore, we investigated whether either of these receptors in the NAC shell contributes to conditioned immunomodulation.

The results of experiment 1 supported the hypothesis that glutamatergic input in the NAC shell regulates conditioned immunomodulation and set the stage for experiment 2 in which we tested the hypothesis that communication within the VTA-BLA-NAC circuitry, via the stimulation of $\mathrm{D}_{1}$ dopamine receptors in the BLA and NMDA receptors in the NAC, is necessary for the expression of conditioned immunomodulation. This experiment took 
advantage of the functional disconnection procedure which has been utilized previously to demonstrate the serial connectivity between brain regions necessary for the expression of motivated behavior in animal models of addiction (Di Ciano \& Everitt, 2004; Fuchs et al., 2007; Belin \& Everitt, 2008; Lasseter et al., 2011). The premise of the functional disconnection procedure is that unilateral antagonism of one brain region combined with contralateral antagonism of another brain region produces greater functional impairment than ipsilateral antagonism of these brain regions if, in fact, intrahemispheric interactions between these brain structures are functionally necessary (Parkinson et al., 2000). This research endeavor was undertaken to explore, for the first time, the involvement of a multisynaptic neural circuit in the control of neural-immune interactions and, specifically, in the expression of heroin-induced conditioned immune alterations.

\section{Materials and Methods}

\section{Animals}

Male Lewis rats, weighing 225-250 g, were purchased from Charles River Laboratories (Raleigh, N.C., USA). Animals were housed individually in plastic cages in a colony room with a reversed light-dark (12h) cycle maintained through artificial illumination. Access to food and water was given ad libitum throughout the experiment except for the time spent in the conditioning chambers when food and water were not available. Animals were given a 2week habituation period before the start of experimental manipulations and were handled regularly during this time. All procedures were approved by the IACUC of the University of North Carolina at Chapel Hill and conformed to National Institutes of Health (NIH) Guidelines on the Care and Use of Laboratory Animals.

\section{Surgical Procedure}

Animals were anesthetized with $0.35 \mathrm{ml}$ intramuscular injections of 9:1 (vol/vol) ketamine hydrochloride $(100 \mathrm{mg} / \mathrm{ml})$ mixed with xylazine $(100 \mathrm{mg} / \mathrm{ml})$ and placed into the stereotaxic apparatus. Animals were implanted with 26-gauge bilateral guide cannula (Plastics One, Roanoke, VA) directed unilaterally toward the BLA (AP -2.5, ML \pm 5.0, DV -6.6) and/or bilaterally towards the NAC shell ( $\mathrm{AP}+1.7, \mathrm{ML} \pm 0.8, \mathrm{DV}-5.4$ ). Coordinates are expressed as millimeters from bregma (Paxinos \& Watson, 1986). Animals were given two weeks to recover from surgery before the start of conditioning trials.

\section{Classical Conditioning Procedure}

To condition heroin's immunomodulatory effects, all animals received five 60-min training sessions in which they received a subcutaneous injection of heroin (diacethylmorphine, 1 $\mathrm{mg} / \mathrm{kg}$, sc; NIDA Drug Supply System, Bethesda, MD), dissolved in $0.9 \%$ sterile saline, immediately prior to placement into a standard conditioning chamber. This heroin dose was selected based on prior experiments in our laboratory showing that it induces conditioned alterations in LPS-induced iNOS and TNF-a mRNA expression in spleen tissue (Lysle \& Ijames, 2002; Szczytkowski \& Lysle, 2007). Training sessions were separated by $48 \mathrm{~h}$.

The conditioning chambers (BRS/LVE, Laurel, MD, USA) were located in a room separate from the animal colony and contained a metal grid floor and cedar bedding to create an environment distinct from the home cage. All conditioning took place during the dark phase of the light cycle and the conditioning chambers were kept dark. Previous studies have shown that animals that undergo this procedure and are later exposed to the previously heroin-paired environment demonstrate robust suppression of immunological parameters, including reduced nitric oxide production and proinflammatory cytokine expression (Lysle \& Ijames, 2002; Szczytkowski \& Lysle, 2008; 2010). 


\section{Behavioral Testing}

Six days following the final conditioning session, animals were re-exposed to the conditioned stimulus (i.e., the conditioning chambers) without further drug administration to determine whether the conditioned stimulus alone would induce alterations in proinflammatory mediators. Thirty minutes prior to the test session, animals received bilateral intra-NAC microinfusions of an ionotropic glutamate antagonist (AMPA/kainate receptor antagonist: CNQX, $2.5 \mu \mathrm{g} / 0.5 \mu \mathrm{l} /$ hemisphere; or NMDA receptor antagonist: AP-5, $1.0 \mu \mathrm{g} / 0.5 \mu \mathrm{l} /$ hemisphere; Experiment 1) or a unilateral microinfusion of the $\mathrm{D}_{1}$ antagonist, $\mathrm{SCH} 23390(2 \mu \mathrm{g} / 0.5 \mu \mathrm{l} / \mathrm{hemisphere})$, into the BLA concomitant with either an ipsilateral or contralateral microinfusion of the NMDA receptor antagonist, AP-5 (1.0 $\mu \mathrm{g} / 0.5 \mu \mathrm{l} /$ hemisphere) into the NAC shell (Experiment 2). Control animals received microinfusions of saline vehicle $(0.5 \mu \mathrm{l} /$ hemisphere infused). The antagonist doses and volumes were chosen based upon previous behavioral/immunological studies that had shown attenuation of cueinduced drug seeking and opioid-induced conditioned immunomodulation at these doses/ volumes of antagonists (Szczytkowski \& Lysle, 2010; Saurer et al., 2006; Giertler et al., 2005 ) and the results of experiment 1 . Injector cannulae extended $2 \mathrm{~mm}$ beyond the tip of the guide cannulae and were left in place for 1 minute after the injection to allow for proper drug diffusion.

Following the microinfusions, two groups of animals were re-exposed to the conditioning chambers (conditioned stimulus, CS) for 60-min in the absence of heroin. The remaining two groups of animals (home cage, $\mathrm{HC}$ ) were returned to their home cages to serve as controls. After the 60-min session in the conditioning chamber or home cage, all animals received a systemic LPS injection $(1000 \mu \mathrm{g} / \mathrm{kg}$, sc) to induce iNOS, TNF-a and IL-6 production and were then returned into their home cages. LPS treatment was used in all groups to produce an immune challenge, as detection of these cytokines and nitric oxide is limited in the absence of an antigenic challenge. Six hours after LPS administration, all animals were sacrificed and samples of spleen tissue and blood were collected for analysis. Spleen tissue was collected because LPS reliably elicits the production nitric oxide in a number of immune cells, including eosinophils, within the spleen (Bandaletova et al., 1993). The 6-hr time point was selected based on previous research in our laboratory showing maximal iNOS induction six hours following LPS administration (Lysle \& How, 2000). Previous studies in our laboratory have included control groups that were exposed to the CS paired with saline during training and animals that received heroin unpaired with the CS (Lysle and Ijames, 2002; Szczytkowski \& Lysle, 2007). Since these controls were not significantly different from animals that were not re-exposed to the CS on test day (HC) they were not included in the current study.

\section{Brain Histology}

To assess cannula placement, Alcian blue dye was microinfused into the NAC shell and/or BLA following sacrifice. Brains were then extracted and post-fixed in a $4 \%$ paraformaldehyde solution. Following fixation, the brains were transferred to a $30 \%$ sucrose solution for cryoprotection and then frozen at $-80^{\circ} \mathrm{C}$ until further analysis. The brains were sectioned in the coronal plane $(50 \mu \mathrm{m})$ and were stained using cresyl violet. Cannula placement was examined on cresyl-violet stained sections and was recorded on appropriate plates of the rat brain atlas of Paxinos and Watson (1997).

\section{Measurement of the Proinflammatory Immune Response}

To determine iNOS, IL-6, and TNF- $a$ expression, real time RT-PCR was performed on tissue samples from the spleen. The spleen was selected for analysis because immunohistochemical localization of iNOS in rats exposed to LPS shows the presence of the iNOS enzyme in a number of immune cells, including macrophages, lymphocytes, and 
neutrophils (Bandaletova et al., 1993). In addition, splenic macrophages also produce IL-6 and TNF-a when activated by LPS. Total RNA was extracted from a section of each of the tissues using TRI-Reagent (Molecular Research Center, Cincinnati, OH), a modification of the original method described by Chomczynski and Sacchi (1987). RNA was quantified spectrophotometrically (GeneQuant II, Pharmacia-Biotech, Piscataway, NJ, USA). For RT$\mathrm{PCR}$, reverse transcription was performed using Oligo(dT) $)_{18}$ primer and Moloney Murine Leukemia Virus-Reverse transcriptase following the protocol of the Advantage RT-for-PCR Kit from Clontech (Palo Alto, CA, USA).

Specific products from the PCR reaction were detected with Universal ProbeLibrary Probes (Roche, Indianapolis, IN). In this method, PCR amplifications are performed using standard protocols, the LightCycler TaqMan Master Real-Time PCR Kit, and the LightCycler instrument (Roche, Indianapolis, IN). A master mix containing all reaction components was prepared for all reactions, with each reaction using a $20 \mathrm{ml}$ mix placed in glass capillary tubes specifically designed for use in the LightCycler system. Primers and probes for genes of interest were as follows: IL-6, 5' -cctggagtttgtgaagaacaact-3' and 5' -

ggaagttggggtaggaagga-3' using probe \#106; iNOS, 5' tgaggattacttcttccagctca-3' and 5'tgggtgtcagagtcttgtgc-3' using probe \#25; and TNF-a, 5' -gggcctccagaactccag-3' and 5'gagcccatttgggaacttct-3' using probe \#98. Primers were synthesized by the Nucleic Acids Core Facility (Lineberger Cancer Center, UNC-Chapel Hill). Copy numbers were generated from by an internal standard curve. Amplifications were carried out for 45 cycles and curves showing fluorescence at each cycle were determined by the computer software (Roche). Samples were pre-incubated for 10 minutes at $95^{\circ} \mathrm{C}$ to activate the Fast-Start Taq DNA polymerase. The cycle temperatures were 95 and $60^{\circ} \mathrm{C}$ for the denaturing and annealing/ extending, respectively. The cycle times were 10 and $30 \mathrm{~s}$ for the denaturing and annealing/ extending, respectively. Fluorescence level was determined at the end of the extending phase for each cycle of PCR. A final cooling phase was carried out at $40{ }^{\circ} \mathrm{C}$ for $30 \mathrm{~s}$. The analysis of the fluorescence level in standards and samples over the course of 45 cycles was used to derive the number of copies of the target molecule in each sample. Additionally, assessments of housekeeping gene expression, L13A, were made to assure comparable quality of RNA among samples. L13A primers were 5'-ccctccacctatgacaaga-3' and 5' ggtacttccacccgacctc-3' with probe \#74. The data are expressed as a ratio of copy number of iNOS (per 10ng cDNA) to the housekeeping gene, L13A (per 10 ng cDNA), based on the standard curve using the Lightcycler software (Roche).

To assess IL-6 and TNF-a protein levels, protein was extracted from a section of each homogenized tissue using freeze/thaw lysis in tris-buffer containing antiproteinases. Protein was quantified spectrophotometrically (Bio-Tek, Model EL312 kinetic reader, Winooski, VT, USA) using Bio-Rad protein dye. To account for variability in tissue size, samples were normalized per unit protein based on the results of the spectrophotometric analysis. The Invitrogen (Carlsbad, CA) rat TNF-a and IL-6 ELISA test kits were used to determine the levels of TNF- $a$ and IL-6 protein in each tissue sample. Briefly, samples and standards were added to microtiter wells coated with antibody that recognizes IL-6 or TNF-a and incubated at room temperature. Wells were washed extensively and then incubated with biotinylated antibody, followed by a second wash and then incubation with Streptavidin-HRP. After the final wash, a chromagen substrate solution was added which reacted with the bound enzyme to produce color. The color intensity developed proportionally to the amount of IL- 6 or TNF-a present in each sample. The enzyme reaction was stopped after 30 minutes, and the absorbance at $450 \mathrm{~nm}$ was measured with a Bio-Tek (Winooski, VT) Model EL312 kinetic reader. A standard curve was obtained by plotting the absorbance versus the corresponding concentrations of the supplied standards. 
The level of nitrite/nitrate in plasma samples was assessed using the Greiss reagent assay. Nitrate and nitrite are formed non-enzymatically when nitric oxide is exposed to oxygen, thus plasma levels of these products indicate the level of nitric oxide production. Total nitrite/nitrate level is determined by the conversion of nitrate to nitrite utilizing nitrate reductase in the presence of NADPH and flavin adenine dinucleotide, and then an assessment using Greiss reagent. Briefly, $6 \mu \mathrm{l}$ of plasma diluted in $44 \mu \mathrm{lof} \mathrm{dH}_{2} \mathrm{O}$ is incubated in the dark for 90 -min with $10 \mu \mathrm{l}$ of nitrate reductase $(1.0 \mathrm{unit} / \mathrm{ml}), 20 \mu \mathrm{l}$ of a 0.31 M phosphate buffer (ph 7.5), $10 \mu \mathrm{l}$ of $0.86 \mathrm{mM}$ NADPH (Sigma), and $10 \mu \mathrm{l}$ of a $0.11 \mathrm{mM}$ flavin adenine dinucleotide in individual wells of a 96-well plate. Then, $200 \mathrm{ml}$ of Griess reagent consisting of a $1: 1(\mathrm{v} / \mathrm{v})$ solution $1 \%$ sulfanilamide in $5.0 \%$ phosphoric acid and $0.1 \% \mathrm{~N}$-(1-napthyl) ethyl-enedamine dihydrochloride in distilled water was added to the samples. The color developed for ten minutes at room temperature after which the absorbance was determined using a spectrophotometer set at $550 \mathrm{~nm}$. All reactions were carried out in triplicate. The total micromolar concentration of nitrite is determined for each sample based on a standard curve. Recovery of nitrate is greater than $95 \%$ using this assay.

\section{Statistical Analysis}

Analysis of variance (ANOVA) was performed on all data sets with antagonist treatment (saline, AP-5, CNQX, ipsilateral SCH23390+AP-5, contralateral SCH23390+AP-5) and context (Home Cage, CS Exposed) as between-subjects factors, as appropriate. Statistically significant interaction effects were followed up by simple main effects tests ( $t$ tests) and planned comparisons evaluating direction-specific hypotheses (one-tail t tests). All analyses were conducted with the level of significance set at $p<0.05$.

\section{Results}

Histology

Figure 1 presents a schematic representation of the cannula placement for both experiments. The symbols on the schematics (Paxinos and Watson, 1997) represent the most ventral point of the infusion cannula tracts for rats that received bilateral microinfusions into the NAC shell for experiment 1 or unilateral microinfusions into the BLA plus the contralateral or ipsilateral NAC for experiment 2. Cannula placements were located in the ventral aspect of the BLA and the ventromedial aspect of the NAC, as intended, in order to minimize diffusion into unintended brain regions. The data of animals with cannula placement outside of the BLA or NAC were not included in the statistical analyses. The resulting sample sizes per group were as follows: bilateral NAC shell Saline/home cage $(n=4)$, bilateral NAC shell Saline/heroin-paired context $(n=5)$, bilateral NAC shell AP-5/home cage $(n=5)$, bilateral NAC shell AP-5/heroin-paired context $(n=5)$, bilateral NAC shell CNQX/home cage $(n=4)$, bilateral NAC shell CNQX/heroin-paired context $(n=5)$, ipsilateral Saline/home cage $(n=5)$, ipsilateral Saline/heroin-paired context ( $\mathrm{n}=5)$, contralateral SCH23390+AP-5/home cage $(\mathrm{n}=5)$, contralateral SCH23390+AP-5/heroin-paired context $(\mathrm{n}=5)$, ipsilateral SCH23390+AP-5/home cage ( $\mathrm{n}=5)$, and ipsilateral SCH23390+AP-5/heroin-paired context $(n=5)$.

\section{Heroin-conditioned suppression of nitric oxide induction requires the stimulation of ionotropic glutamate receptors in the nucleus accumbens shell}

The first study investigated the effect of bilateral intra-NAC shell microinfusions of the NMDA glutamate receptor antagonist, AP-5, or the AMPA/kainate glutamate receptor antagonist, CNQX, on the expression of heroin-conditioned suppression of proinflammatory mediators. Six days following the final conditioning session, animals were re-exposed to the previously heroin-paired environment (CS Exposed) or remained in their home cages (Home 
Cage) for $60 \mathrm{~min}$. AP-5, CNQX, or saline was administered 30 minutes prior to the test session, whereas LPS was administered $1 \mathrm{hr}$ after the test session.

Figure 2 shows the effects of AP-5 and CNQX on the LPS-induced expression of splenic iNOS mRNA levels (upper panel) and serum nitrite/nitrate levels (lower panel) in the groups exposed to the previously heroin-paired environment or the home cage prior to LPS challenge. Because nitric oxide is a gaseous molecule with a short half-life, its production was measured indirectly by analyzing iNOS enzyme mRNA levels in the spleen and the degradation products nitrite and nitrate in the serum. The ANOVA for LPS-induced iNOS copy number in the spleen revealed a significant antagonist by context interaction effect $[F(2,21)=4.537, P<0.05]$, but no main effects of antagonist treatment or context. In addition, a separate ANOVA for serum nitrite/nitrate levels revealed a significant antagonist by context interaction effect $[\mathrm{F}(2,21)=10.123, P<0.01)$ as well as significant main effects of antagonist treatment $[\mathrm{F}(2,21)=4.629, \mathrm{P}<0.05]$ and context $[\mathrm{F}(1,21)=8.593 ; \mathrm{P}<0.01]$. The saline-treated group exposed to the previously heroin-paired environment exhibited lower splenic iNOS mRNA levels and serum nitrite/nitrate concentration than the saline-treated home cage control group $\left(\mathrm{t}_{(6)}=2.878 ; \mathrm{P}<0.05 ; \mathrm{t}_{(6)}=5.788 ; \mathrm{P}<0.01\right.$, respectively). These changes were similar in intensity to the unconditioned suppression observed following the administration of heroin itself (Lysle \& How, 2000). Most importantly, unlike in the salinetreated groups, there were no significant differences between the AP-5-treated or the CNQX-treated group exposed to the previously heroin-paired environment and their respective home cage control group in splenic iNOS mRNA levels and serum nitrite/nitrate concentration. These results demonstrate that NMDA or AMPA/kainate receptor antagonism in the NAC shell blocks the heroin-conditioned suppression in iNOS mRNA expression and nitrite/nitrate concentration, suggesting a role for these receptors in heroin-induced conditioned immunomodulation.

\section{Heroin-conditioned suppression of TNF- $\alpha$ production requires the stimulation of ionotropic glutamate receptors in the nucleus accumbens shell}

Exposure to a previously heroin-paired environment induces a conditioned suppression of the proinflammatory cytokine, TNF-a (Szczytkowski \& Lysle, 2008). Figure 3 illustrates that this conditioned suppressive effect of heroin on TNF-a expression is blocked by antagonism of glutamate AMPA/kainate or NMDA receptors within the NAC shell. The ANOVA for splenic TNF-a mRNA levels revealed an antagonist treatment by context interaction effect $[\mathrm{F}(2,21)=3.831, p<0.05]$ but no antagonist treatment or context main effects. Similarly, the ANOVA for splenic TNF-a protein levels revealed an antagonist treatment by context interaction effects $[\mathrm{F}(2,21)=3.737, p<0.05]$ and an antagonist treatment main effect $[\mathrm{F}(2,21)=3.901, p<0.05]$ but no context main effect. In line with our previous experiments, the saline-treated group exposed to the previously heroin-paired environment exhibited significantly lower levels of TNF-a mRNA and protein in the spleen as compared to the saline-treated home cage control group (one-tail $\mathrm{t}_{(6)}=1.995 ; \mathrm{P}<0.05 ; \mathrm{t}_{(6)}=2.514$; $\mathrm{P}<0.05$, respectively). Most importantly, unlike in the saline-treated groups, there were no significant differences between the AP-5-treated or the CNQX-treated group exposed to the previously heroin-paired environment and the respective home cage control group in TNF- $a$ mRNA and protein levels in the spleen. These data indicate that NMDA or AMPA/kainate receptor antagonism in the NAC shell attenuated the heroin-conditioned suppression in LPSinduced TNF-a expression.

\section{Heroin-conditioned suppression of IL- 6 production requires the stimulation of ionotropic glutamate receptors in the nucleus accumbens shell}

Figure 4 shows that the suppressive effect of heroin on the production of the proinflammatory cytokine, IL-6, can be conditioned to environmental stimuli and, again, this 
conditioned effect is reduced by antagonism of either AMPA/kainate or NMDA receptors within the NAC shell. This effect was evident at the mRNA, but not the protein level, in the spleen. The ANOVA for splenic IL-6 mRNA levels revealed a significant antagonist treatment by context interaction effect in $[\mathrm{F}(2,21)=4.021, p<0.05]$ but no antagonist treatment or context main effects. Although the direction of the effect was as expected, the ANOVA for splenic IL- 6 protein levels did not indicate a significant antagonist treatment by context interaction effect $[\mathrm{F}(2,21)=2.341, \mathrm{p}=.121]$ or main effects. In line with our previous experiments, the saline-treated group exposed to the previously heroin-paired environment on the test day exhibited significantly lower levels of IL-6 mRNA in the spleen compared to the saline-treated home cage control group $\left(\mathrm{t}_{(6)}=3.923 ; \mathrm{P}<0.01\right)$. Again, although the expected effect for IL-6 protein was evident the t-test did not achieve statistical significance. Conversely, there were no significant differences between the AP-5-treated or the CNQXtreated group exposed to the previously heroin-paired environment and its respective home cage control group in IL-6 mRNA levels in the spleen, showing that antagonism of either AMPA/kainate or NMDA receptors within the NAC shell blocked the heroin-conditioned suppression of LPSinduced IL-6 mRNA expression.

\section{Heroin-conditioned suppression of nitric oxide production depends on the integrity of the VTA-BLA-NAC circuit}

Experiment 2 investigated the expression of heroin-induced conditioned suppression of proinflammatory mediators following functional disconnection of a circuitry comprised of the VTA, D1-receptor-bearing neurons in the BLA, and NMDA receptor-bearing neurons in the NAC shell. On the test day, animals were re-exposed to the previously heroin-paired environment for $60 \mathrm{~min}$ or remained in the home cage. To disconnect the above circuitry prior to testing of the conditioned response, animals received a unilateral microinfusion of the $\mathrm{D}_{1}$ antagonist, $\mathrm{SCH} 23390$, into the BLA coupled with a unilateral microinfusion of the NMDA antagonist, AP-5, into the contralateral NAC shell. One control group received ipsilateral infusions of SCH23390 into the BLA and AP-5 into the NAC. Additional control groups received saline microinfusions into the contralateral or ipsilateral BLA and the NAC shell.

Figure 5 shows the mean levels of LPS-induced iNOS mRNA expression in the spleen (upper panel) and the LPS-induced nitrite/nitrate concentrations in the serum (lower panel) for each group. The ANOVA for splenic iNOS mRNA levels revealed a significant antagonist treatment by context interaction effect $[\mathrm{F}(2,24)=5.252, P<0.05]$, as well as significant context $\mathrm{F}(1,24)=18.647, \mathrm{P}<0.01]$ and antagonist treatment main effects $[F(2,24)=10.675, P<0.01]$. Similarly, the ANOVA for serum nitrite/nitrate concentration revealed a significant antagonist treatment by context interaction effect $[\mathrm{F}(2,24)=6.677$, $P<0.05]$, as well as significant context $[\mathrm{F}(1,24)=8.737, \mathrm{P}<0.01]$ and antagonist treatment main effects $[\mathrm{F}(2,24)=8.474, \mathrm{P}<0.01]$. The saline-treated group exposed to the previously heroin-paired environment on the test day exhibited significantly lower splenic iNOS copy number and serum nitrite/nitrate concentration compared to the saline-treated home cage control group $\left(\mathrm{t}_{(8)}=6.884 ; \mathrm{P}<0.01 ; \mathrm{t}_{(8)}=5.371 ; \mathrm{P}<0.01\right.$, respectively). These data reconfirm our earlier findings indicating that exposure to a previously heroin-paired environment suppresses splenic iNOS mRNA expression and serum nitrite/nitrate levels. Similarly, the group that received ipsilateral $\mathrm{SCH} 23390$ plus AP-5 treatment prior to exposure to the previously heroin-paired environment exhibited significantly lower iNOS copy number and nitrite/nitrate concentration compared to the ipsilaterally-treated home cage control group $\left(\mathrm{t}_{(8)}=5.131 ; \mathrm{P}<0.01 ; \mathrm{t}_{(8)}=4.519 ; \mathrm{P}<0.01\right.$, respectively). Most importantly, however, there was no difference between the group that received contralateral SCH23390 plus AP-5 treatment prior to exposure to the previously heroin-paired environment and the contralaterally-treated home cage control group in iNOS copy number or nitrite/nitrate concentration. These 
findings indicate that functional disconnection of the VTA-BLA-NAC circuitry blocks the heroin-conditioned suppression of LPS-induced nitric oxide production.

\section{Heroin-conditioned suppression of TNF- $\alpha$ expression depends on the integrity of the VTA- BLA-NAC circuitry}

Figure 6 shows the mean levels of LPS-induced TNF-a expression for each group. The ANOVA for splenic TNF- $a$ mRNA levels revealed significant context $[F(1,24)=6.171$, $\mathrm{P}<0.05]$ and antagonist treatment main effects $[\mathrm{F}(1,24)=3.498, \mathrm{P}<0.05]$ but no antagonist treatment by context interaction effect. Furthermore, the ANOVA for TNF-a protein levels revealed a significant context main effect $[\mathrm{F}(1,24)=5.06, \mathrm{P}<0.05]$ but not antagonist treatment main effect or antagonist treatment by context interaction effect. However, planned comparisons indicated that the groups that received saline or ipsilateral SCH23390 plus AP-5 treatment prior to exposure to the previously heroin-paired environment exhibited lower TNF-a mRNA $\left(\mathrm{t}_{(8)}=3.711 ; \mathrm{P}<0.01 ; \mathrm{t}_{(8)}=2.832 ; \mathrm{P}<0.05\right.$, respectively) and protein levels $\left(\mathrm{t}_{(8)}=2.426 ; \mathrm{P}<0.05 ; \mathrm{t}_{(8)}=2.312 ; \mathrm{P}<0.05\right.$, respectively) compared to the respective home cage control groups. Conversely, there were no differences between the groups that received contralateral SCH23390 and AP-5 prior to exposure to the previously heroin-paired environment and the respective home cage control group in TNF- $a$ mRNA or protein levels. These findings indicate that functional disconnection of the VTA-BLA-NAC circuitry blocks the heroin-conditioned suppression of LPS-induced TNF- $a$ expression.

\section{Heroin-conditioned suppression of IL-6 expression depends on the integrity of the VTA- BLA-NAC circuitry}

Figure 7 shows the suppressive effect of heroin on IL-6 mRNA and protein expression in the spleen for each group. The ANOVAs for splenic IL-6 mRNA and protein levels revealed significant context main effects $[\mathrm{F}(1,24), \mathrm{P}<0.01 ; \mathrm{F}(1,24)=11.514, \mathrm{P}<0.01$, respectively] but no antagonist treatment main or antagonist treatment by context interaction effect. However, planned comparison revealed that the groups that received saline or ipsilateral SCH23390 plus AP-5 treatment prior to exposure to the previously heroin-paired environment exhibited lower IL-6 mRNA expression $\left(\mathrm{t}_{(8)}=4.12, \mathrm{P}<0.01\right.$; one-tail $\mathrm{t}_{(8)}=2.273$; $\mathrm{P}<0.05$, respectively) and IL-6 protein levels $\left(\mathrm{t}_{(8)}=4.569 ; \mathrm{P}<0.01 ;\right.$ one-tail $\mathrm{t}_{(8)}=2.02 ; \mathrm{P}<0.05$, respectively) compared to the respective home cage control groups. Conversely, there were no differences between the groups that received contralateral SCH23390 and AP-5 prior to exposure to the previously heroin-paired environment and the respective home cage control group in splenic IL-6 mRNA and protein levels. These findings indicate that functional disconnection of the VTA-BLA-NAC circuitry blocks the heroin-conditioned suppression of LPS-induced IL-6 expression.

\section{Discussion}

Although our laboratory and others have previously identified key brain areas involved in conditioned immunomodulation, the experiments reported here are the first to identify a specific neural circuit critical for the expression of the effects of heroin-related cues on immune functioning. Specifically, they indicate that stimulation of ionotropic glutamate receptors in the NAC shell as well as communication between the VTA, $\mathrm{D}_{1}$ dopamine receptor-bearing neurons in the BLA, and NMDA receptor-bearing neurons in the NAC shell are necessary for the ability of a heroin-paired context to suppress the production of proinflammatory modulators in response to LPS immune challenge. The production of proinflammatory modulators is a critical component of host immune response to pathogenic challenge and any disruption of this process in current or recovering heroin users may manifest as a decreased ability to combat infectious diseases even after achieving drug abstinence. This, in turn, increases the risk of opportunistic infections and can result in other 
problems related to decreased immunity, such as deficient antibody responses to vaccination.

The results of experiment 1 demonstrate that glutamatergic signaling within the NAC shell plays a critical role in the conditioned effects of heroin on proinflammatory mediators. In particular, antagonism of either NMDA or AMPA/kainate receptors within the NAC shell blocked the expression of heroin-conditioned suppression of LPS-induced nitric oxide, TNF$a$, and IL-6 expression providing exciting new information regarding the role of the NAC in heroin-induced conditioned immunomodulation. Similarly, NMDA or AMPA/kainate receptor antagonism in the NAC prevents drug context-induced drug-seeking behavior (Xie et al., 2011) and 7-OH-DPAT-conditioned place preference (Biondo et al., 2005), conditioned behaviors based on associations between environmental stimuli and the primary rewarding effects of 7-OH-DPAT. Together, these and the present findings indicate a general role for NAC NMDA and AMPA receptors in Pavlovian conditioned responses, including conditioned immunomodulatory responses.

Recent research from our laboratory revealed that antagonism of dopamine $\mathrm{D}_{1}$, but not $\mathrm{D}_{2}$, receptors within the BLA blocks the conditioned effects of heroin on proinflammatory mediators (Szczytkowski \& Lysle, 2010). Importantly, the BLA directly innervates the NAC via glutamatergic afferents (Wright \& Groenewegen, 1995; Wright et al., 1996; Sesack \& Grace, 2010). Furthermore, functional disconnection studies have demonstrated that the establishment of conditioned reinforcers and second-order Pavlovian conditioning are dependent on interactions between the BLA and the NAC (Baldwin et al., 2000; Setlow et al., 2002; Di Ciano \& Everitt, 2004), supporting the hypothesis that communication within the VTA-BLA-NAC circuitry may be necessary for the expression of conditioned immunomodulation. To investigate this hypothesis, we used a functional disconnection procedure (Setlow et al., 2002; Di Ciano \& Everitt, 2004; Fuchs et al., 2007; Lasseter et al., 2011). In addition, we took advantage of the fact that, in the rat, the primary source of dopamine to the BLA is the VTA (Ford et al, 2006), in order to obtain a triple disconnection manipulation. Accordingly, in experiment 2, unilateral intra-BLA administration of the $\mathrm{D}_{1}$ receptor antagonist, SCH23390, was coupled with contralateral intra-NAC shell administration of the NMDA antagonist, AP-5, in order to functionally disconnect the VTABLA-NAC neural circuit prior to the testing of the conditioned immune response.

Remarkably, functional disconnection of the VTA-BLA-NAC neural circuit blocked the expression of heroin-conditioned suppression of the LPS-induced proinflammatory response. Conversely, ipsilateral manipulation of the same neural circuit, which antagonizes the same amount of neural tissue but leaves communication within the VTA-BLA-NAC neural circuit intact in one hemisphere, failed to impair the heroin-conditioned suppression of this proinflammatory response. These data indicate that sequential information processing by the VTA, $\mathrm{D}_{1}$ dopamine-bearing neurons in the BLA, and NMDA receptor-bearing neurons in the NAC shell is necessary for heroin-induced conditioned immunomodulation and define, for the first time, a specific neural circuit involved in neural-immune interactions.

It important to note that additional interactions between the VTA, BLA, and NAC and communication with other brain regions are likely to critically contribute to heroin-induced conditioned immunomodulation. Thus, further characterization of the larger neural circuit responsible for this conditioned immune effect will be imperative. First, the present study identifies the BLA as a necessary source of glutamatergic input to the NAC for the expression of conditioned immunomodulation; however, the NAC receives glutamatergic input from numerous other brain regions, including the dorsal hippocampus and prelimbic cortex, which may be elements of the circuitry. In fact, preliminary studies in our laboratory suggest that the dorsal hippocampus also plays a role in heroin-conditioned suppression of 
LPS-induced immune responses (Szczytkowski et al., unpublished observations). Future disconnection studies will need to establish, however, whether the dorsal hippocampus contributes to these responses as part of the currently known or a separate neural circuit. Second, our laboratory has shown that intra-NAC shell administration of the dopamine $\mathrm{D}_{1}$ receptor antagonist, $\mathrm{SCH} 23390$, blocks the unconditioned effects of morphine and the conditioned effects of morphine-paired environmental stimuli on natural killer cell activity and nitric oxide production (Saurer et al., 2006; Saurer et al., 2009). Taken together with the present findings, these data indicate that both glutamatergic and dopaminergic receptor stimulation within the NAC is necessary for the expression of opioid-induced conditioned immunomodulation. Furthermore, pyramidal cell projections from the BLA synapse in close proximity to dopamine axons on medium spiny neurons of the NAC (Johnson et al., 1994, Kelley et al., 1982 and Robinson \& Beart, 1988), suggesting that conditioned immune regulation may be a result of complex interaction between dopamine and glutamate within the NAC. Third, the hypothalamus likely acts as an interface between the central nervous system and autonomic centers that control peripheral immune response, including those observed in the present study in the spleen and blood plasma. Consistent with this, various hypothalamic nuclei exhibit robust Fos protein expression, a marker of neural activation, in association with morphine-induced immunomodulation (Saurer \& Lysle, unpublished observation). Thus, future studies will ascertain whether neural activity within these regions of the hypothalamus is also integral to opioid-conditioned immunomodulatory responses.

While the exact peripheral mechanisms modulating the alterations in proinflammatory mediators observed in response to exposure to opioid-associated drug cues are unknown, research has revealed potential mechanisms. Given the connectivity of the hypothalamus with the autonomic nervous system and its control over the release of various peripheral neuroendocrine mediators, this brain region may serve as the relay between the CNS and the immune system. For example, cocaine-associated cues induce concomitant alterations in immune functioning, including TNF-a production, and in corticosterone levels, suggesting the HPA axis may be involved in drug cue-mediated conditioned immunomodulation (Kubera et al., 2008). Alternatively, the sympathetic nervous system innervates both primary and secondary lymphoid tissues and releases molecules that interact with receptors on immune cells (Williams et al., 1981; Felten et al., 1984). In fact, sympathetic innervation of the spleen provides some of the most concrete evidence for communication between the nervous and immune systems through the release of norepinephrine (and other chemicals) from sympathetic nerve fibers onto immune cells in this organ. In support of this possibility, previous research from our laboratory has shown that the suppression of splenic mitogenic responsiveness observed following exposure to an aversive CS can be blocked by administration of the beta-adrenergic receptor antagonist, propanolol (Lysle et al., 1991). Similarly, the expression of a subset of morphine-induced conditioned immune alterations is blocked by systemic administration of the non-selective peripheral $\beta$-adrenergic receptor antagonist, nadolol (Coussons-Read et al., 1994). The sympathetic nervous system may also be involved in the unconditioned effects of morphine on immunity as beta-adrenergic receptor antagonistm attenuate the morphine-induced suppression of lymphocyte proliferation (Fecho et al., 1993). Furthermore, the conditioned and unconditioned effects of opiates on NK cell cytotoxicity appears to be mediated by neuropeptide Y, a peptide transmitter co-released with norepinephrine by the sympathetic nervous system (Saurer et al. 2006; 2008). Collectively these data suggest a possible role for the hypothalamus and the sympathetic nervous system in the modulation of opiate-induced conditioned immunomodulation.

Exposure to drug-associated environmental stimuli may have widespread implications for the health outcomes of both current and former opiate users. For this reason, it is crucial that the mechanisms by which previously heroin-paired stimuli alter the immune response are 
elucidated. A clear understanding of the neurotransmitters and neural circuitry involved in heroin-conditioned immunomodulation will be needed for the targeted development of pharmaceuticals that restore immune function in susceptible populations, allowing pharmacotherapeutic intervention before infections lead to irreversible organ damage and other detrimental health consequences. These effects need to be factored into the comprehensive treatment - including substitution therapy and pain management - of both current and former opiate users.

\section{Acknowledgments}

This research was supported by National Institute on Drug Abuse grant DA25667. JLS was supported by the Seeding Postdoctoral Innovators in Research and Education (SPIRE) program funded by the National Institutes of Health, Minority Opportunities in Research division of the National Institute of General Medical Sciences (NIGMS) grant K12GM000678.

\section{REFERENCES}

Backstrom P, Hyytia P. Involvement of AMPA/kainate, NMDA, and mGlu5 receptors in the nucleus accumbens core in cue-induced reinstatement of cocaine seeking in rats. Psychopharmacology. 2007; 192(4):571-580. [PubMed: 17347848]

Baldwin AE, Holahan MR, Sadeghian K, Kelley AE. N-methyl-D-aspartate receptor-dependent plasticity within a distributed corticostriatal network mediates appetitive instrumental learning. Behav Neurosci. 2000; 114(1):84-98. [PubMed: 10718264]

Bandaletova T, Brouet I, Bartsch H, Sugimura T, Esumi H, Ohshima H. Immunohistochemical localization of an inducible form of nitric oxide synthase in various organs of rats treated with Propionibacteriumacnes and lipopolysaccharide. Apmis. 1993; 101:330-336. [PubMed: 7686760]

Belin D, Everitt BJ. Cocaine seeking habits depend upon dopamine-dependent serial connectivity linking the ventral with the dorsal striatum. Neuron. 2008; 57(3):432-441. [PubMed: 18255035]

Benscsics A, Elenkov IJ, Vizi ES. Effect of morphine on lipopolysaccharide-induced tumor necrosis factor-alpha in vivo: involvement of the sympathetic nervous system. J Neuroimmunol. 1997; 73(12):1-6. [PubMed: 9058753]

Biondo AM, Clements RL, Hayes DJ, Eshpeter B, Greenshaw AJ. NMDA or AMPA/kainite receptor blockade prevents acquisition of conditioned place preference induced by $\mathrm{D}(2 / 3)$ dopamine receptor stimulation in rats. Psychopharmacology. 2005; 179(1):189-197. [PubMed: 15744543]

Chao CC, Molitor TW, Close K, Hu S, Peterson PK. Morphine inhibits the release of tumor necrosis factor in human peripheral blood mononuclear cell cultures. Int J Immunopharmacol. 1993; 15:447453. [PubMed: 8389331]

Chen J, Lin W, Wang W, Shao F, Yang J, Wang B, Kuang F, Duan X, Ju G. Enhancement of antibody production and expression of c-Fos in the insular cortex in response to a conditioned stimulus after a single-trial learning paradigm. Behav Brain Res. 2004; 154 (2):557-565. [PubMed: 15313045]

Chomczynski P, Sacchi N. Single-step method of RNA isolation by acide guanidinium thiocyanatephenol-chloroform extraction. Analytical Biochemistry. 1987; 162:156-159. [PubMed: 2440339]

Clark JD, Shi X, Li X, Qiao Y, Liang D, Angst MS, Yeomans DC. Morphine reduces local cytokine expression and neutrophil infiltration after incision. Mol Pain. 2007; 3:28. [PubMed: 17908329]

Coussons-Read ME, Dykstra LA, Lysle DT. Pavlovian conditioning of morphine-induced alterations of immune status: Evidence for peripheral beta-adrenergic receptor involvement. Brain, Behavior, and Immunity. 1994; 8:204-217.

Di Ciano P, Everitt BJ. Direct interactions between the basolateral amygdala and the nucleus accumbens core underlie cocaine-seeking behavior by rats. J Neurosci. 2004; 24(32):7167-7173. [PubMed: 15306650]

Fecho K, Dykstra LA, Lysle DT. Evidence for beta adrenergic receptor involvement in the immunomodulatory effects of morphine. J Pharmacol Exp Ther. 1993; 265(3):1079-1087. [PubMed: 8389851]

Fecho K, Maslonek KA, Dykstra LA, Lysle DT. Assessment of the involvement of central nervous system and peripheral opioid receptors in the immunomodulatory effects of acute morphine 
treatment in rats. Journal of Pharmacology and Experimental Therapeutics. 1996a; 276:626-636. [PubMed: 8632330]

Fecho K, Maslonek KA, Dykstra LA, Lysle DT. Evidence for sympathetic and adrenal involvement in the immunomodulatory effects of acute morphine treatment in rats. Journal of Pharmacology and Experimental Therapeutics. 1996b; 277:633-645. [PubMed: 8627540]

Felten DL, Livnat S, Felten SY, Carlson SL, Bellinger DL, Yeh P. Sympathetic innervation of lymph nodes in mice. Brain Research Bulletin. 1984; 13:693-699. [PubMed: 6532515]

Ford CP, Mark GP, Williams JT. Properties and opioid inhibition of mesolimbic dopamine neurons vary according to target location. J Neurosci. 2006; 26(10):2788-2797. [PubMed: 16525058]

Fuchs RA, Eaddy JL, Su ZI, Bell GH. Interactions of the basolateral amygdala with the dorsal hippocampus and dorsomedial prefrontal cortex regulate drug context-induced reinstatement of cocaine-seeking in rats. Eur J Neurosci. 2007; 26(2):487-498. [PubMed: 17650119]

Giertler C, Bohn I, Hauber W. Involvement of NMDA and AMPA/KA receptors in the nucleus accumbens core in instrumental learning guided by reward-predictive cues. Eur J Neurosci. 2005; 21(6):1689-1702. [PubMed: 15845096]

Gremel CM, Cunningham CL. Involvement of amygdala dopamine and nucleus accumbens NMDA receptors in ethanol-seeking behavior in mice. Neuropsychopharmacology. 2009; 34(6):14431453. [PubMed: 18830237]

Hotsenpiller G, Giorgetti M, Wolf ME. Alterations in behavior and glutamate transmission following presentation of stimuli previously associated with cocaine exposure. Eur J Neurosci. 2001; 14(11): 1843-1855. [PubMed: 11860480]

Johnson LR, Aylward RL, Hussain Z, Totterdell S. Input from the amygdala to the rat NAC: its relationship with tyrosine hydroxylase immunoreactivity and identified neurons. Neuroscience. 1994; 61(4):851-865. [PubMed: 7530817]

Kelley AE, Domesick VB, Nauta JH. The amygdalo-striatial projection in the rat: An anatomical study by anterograde and retrograde tracing methods. Neuroscience. 1982; 7:615-630. [PubMed: 7070669]

Kubera M, Filip M, Budziszewska B, Basta-Kaim A, Wydra K, Leskiewicz M, Regulska M, JaworskaFeil L, Przegalinski E, Machowska A, Lason W. Immunosuppression induced by a conditioned stimulus associated with cocaine self-administration. J Pharmacol Sci. 2008; 107(4):361-369. [PubMed: 18719314]

Lasseter HC, Wells AM, Xie X, Fuchs RA. Interaction of the basolateral amygdala and orbitofrontal cortex is critical for drug context-induced reinstatement of cocaine-seeking behavior in rats. Neuropsychopharmacology. 2011; 36(3):711-720. [PubMed: 21124303]

Lysle DT, Coussons ME, Watts VJ, Bennett EH, Dykstra LA. Morphine-Induced Alterations of Immune Status - Dose Dependency, Compartment Specificity and Antagonism by Naltrexone. Journal of Pharmacology and Experimental Therapeutics. 1993; 265:1071-1078. [PubMed: 7685383]

Lysle DT, Cunnick JE, Maslonek KA. Pharmacological manipulation of immune alterations induced by an aversive conditioned stimulus: Evidence for a betaadrenergic receptor-mediated Pavlovian conditioning process. Behavioral Neuroscience. 1991; 105:443-449. [PubMed: 1650562]

Lysle DT, Hoffman KE, Dykstra LA. Evidence for the involvement of the caudal region of the periaqueductal gray in a subset of morphine-induced alterations of immune status. Journal of Pharmacology and Experimental Therapeutics. 1996; 277:1533-1540. [PubMed: 8667220]

Lysle DT, How T. Heroin modulates the expression of inducible nitric oxide synthase. Immunopharmacology. 2000; 46:181-192. [PubMed: 10741899]

Lysle DT, Ijames SG. Heroin-associated environmental stimuli modulate the expression of inducible nitric oxide synthase in the rat. Psychopharmacology. 2002; 164:416-422. [PubMed: 12457272]

McDonald AJ. Topographical organization of amygdaloid projections to the caudatoputamen, nucleus accumbens, and related striatal-like areas of the rat brain. Neuroscience. 1991; 44:15-33. [PubMed: 1722890]

Nelson CJ, Carrigan KA, Lysle DT. Naltrexone administration attenuates surgery-induced immune alterations in rats. J Surg Res. 2000; 94(2):172-177. [PubMed: 11104658] 
Pacifici R, di Carlo S, Bacosi A, Pichini S, Zuccaro P. Pharmocokinetics and cytokine production in heroin and morphine-treated mice. Int J Immunopharmacol. 2000; 22:603-614. [PubMed: 10988355]

Pacheco-Lopez G, Niemi MB, Kou W, Harting M, Fandrey J, Schedlowski M. Neural substrates for behaviorally conditioned immunosuppression in the rat. J Neurosci. 2005; 25(9):2330-2337. [PubMed: 15745959]

Parkinson JA, Willoughy PJ, Robbins TW, Everitt BJ. Disconnection of the anterior cingulate cortex and nucleus accumbens core impairs Pavlovian approach behavior: further evidence for limbic cortical-ventral striatopallidal systems. Behav Neurosci. 2000; 114(1):42-63. [PubMed: 10718261]

Paxinos, G.; Watson, C. The Rat Brain in Stereotaxic Coordinates. San Diego: Academic Press; 1997.

Ramirez-Amaya V, Alvarez-Borda B, Bermudez-Rattoni F. Differential effects of NMDA-induced lesions into the insular cortex and amygdala on the acquisition and evocation of conditioned immunosuppression. Brain Behav Immun. 1998; 12(2):149-160. [PubMed: 9646939]

Ramirez-Amaya V, Alvarez-Borda B, Ornsby CE, Martinez RD, Perez-Montfort R, Bermudez-Rattoni F. Insular cortex lesions impair the acquisition of conditioned immunosuppression. Brain Behav Immu. 1996; 10(2):103-114.

Ramirez-Amaya V, Bermudez-Rattoni F. Conditioned enhancement of antibody production is disrupted by insular cortex and amygdala but not hippocampal lesions. Brain Behav Immun. 1999; 13(1):46-60. [PubMed: 10371677]

Robinson TG, Beart PM. Excitant amino acid projections from rat amygdala and thalamus to NAC. Brain Res Bull. 1988; 20(4):467-471. [PubMed: 3293707]

Rodriguez-Borrero E, Bernardo Colon A, Burgos-Martir MA, Alvarez Carillo JE, del Campo YE, Abella-Ramirez C, Maldonado-Vlaar CS. NMDA antaonist AP-5 increase environmentally induced cocaine-conditioned locomotion within the nucleus accumbens. Pharmacol Biochem Behav. 2006; 85(1):178-184. [PubMed: 16963113]

Saurer TB, Carrigan KA, Ijames SG, Lysle DT. Suppression of natural killer cell activity by morphine is mediated by the nucleus accumbens shell. J Neuroimmunol. 2006; 173(1-2):3-11. [PubMed: 16364456]

Saurer TB, Ijames SG, Carrigan KA, Lysle DT. Neuroimmune mechanisms of opioid-mediated conditioned immunomodulation. Brain, Behavior, and Immunity. 2008; 22:89-97.

Saurer TB, Ijames SG, Lysle DT. Neuropeptide Y Y1 receptors mediate morphine-induced reductions of natural killer cell activity. Journal of Neuroimmunology. 2006; 177:18-26. [PubMed: 16766046]

Saurer TB, Ijames SG, Lysle DT. Evidence for the nucleus accumbens as a neural substrate of heroininduced immune alterations. J Pharmacol Exp Ther. 2009; 329(3):1040-1047. [PubMed: 19258519]

Sesack SR, Grace AA. Cortico-Basal Ganglia reward network: microcircuitry. Neuropsychopharmacology. 2010; 35(1):27-47. [PubMed: 19675534]

Setlow B, Holland PC, Gallagher M. Disconnection of the basolateral amygdala complex and nucleus accumbens impairs appetitive second-order conditioned responses. Behav Neurosci. 2002; 116(2): 267-275. [PubMed: 11996312]

Szczytkowski JL, Lysle DT. Conditioned effects of heroin on the expression of inducible nitric oxide synthase in the rat are susceptible to extinction and latent inhibition. Psychopharmacology. 2007; 191:879-889. [PubMed: 17211650]

Szczytkowski JL, Lysle DT. Conditioned effects of heroin on proinflammatory mediators require the basolateral amygdala. European Journal of Neuroscience. 2008; 28(9):1867-1876. [PubMed: 18973600]

Szczytkowski JL, Lysle DT. Dopamine D1 receptors within the basolateral amygdala mediate heroininduced conditioned immunomodulation. J Neuroimmunol. 2010; 226(1-2):38-47. [PubMed: 20605224]

Weber RJ, Pert A. The periaqueductal gray matter mediates opiate-induced immunosuppression. Science. 1989; 245(4914):188-190. [PubMed: 2749256] 
Williams JM, Peterson RG, Shea PA, Schmedtje JF, Bauer DC, Felten DL. Sympathetic innervation of murine thymus and spleen: Evidence for a functional link between the nervous and immune systems. Brain Research Bulletin. 1981; 6:83-94. [PubMed: 7193506]

Wright CI, Beijer AVJ, Groenewegen H. Basal amygdaloid complex afferents to the rat nucleus accumbens are compartmentally organized. J Neurosci. 1996; 16:1877-1893. [PubMed: 8774456]

Wright CI, Groenewegen HJ. Patterns of convergence and segregation in the medial nucleus accumbens of the rat: relationships of prefrontal cortical, midline thalamic, and basal amygdaloid afferents. J Comp Neurol. 1995; 361(3):383-403. [PubMed: 8550887]

Xie X, Lasseter HC, Ramirez DR, Ponds KL, Wells AM, Fuchs RA. Subregion-specific role of glutamate receptors in the nucleus accumbens on drug context-induced reinstatement of cocaineseeking behavior in rats. Addict Biol. 2011 


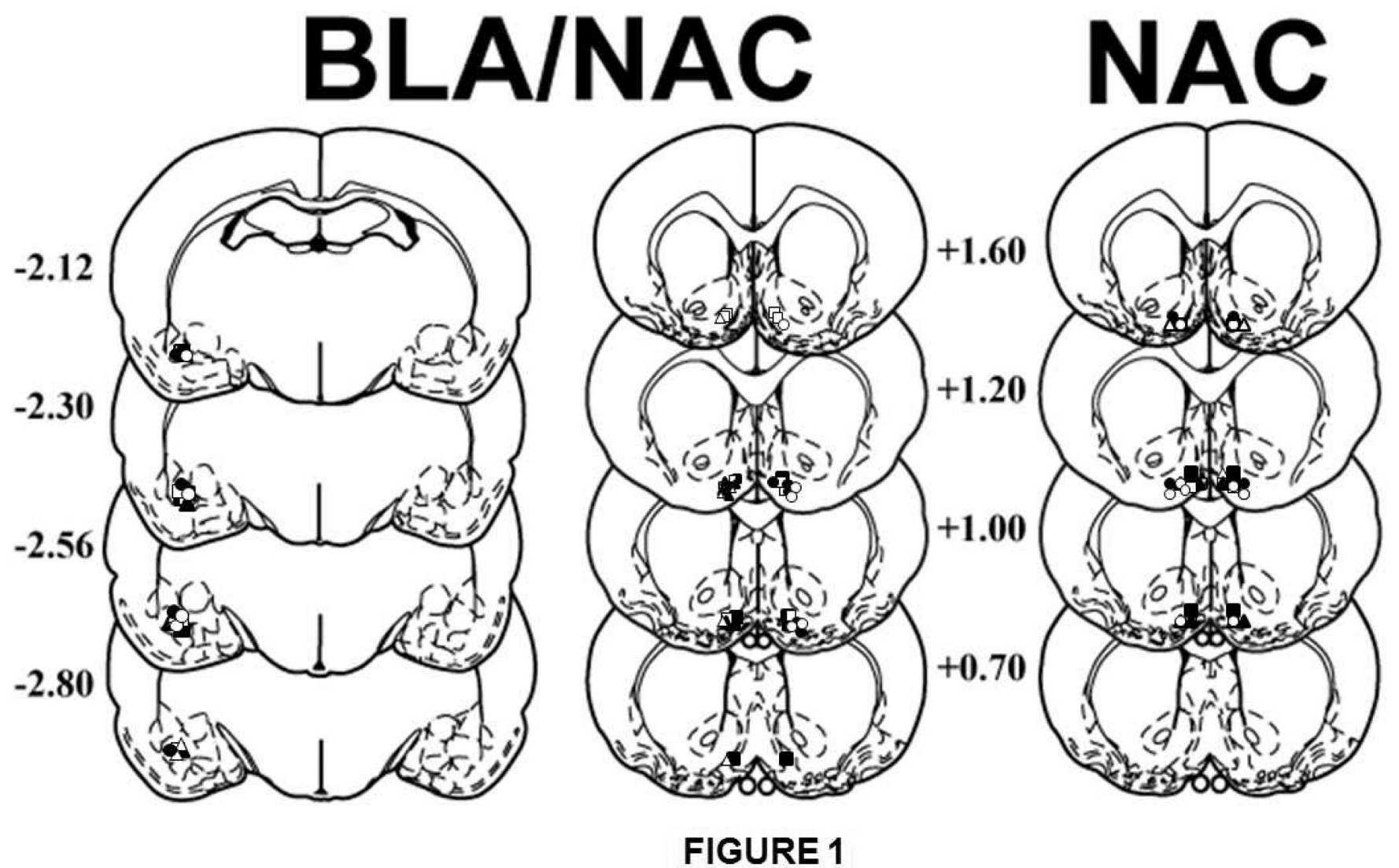

Figure 1.

Schematic representation of injection cannula placements. The symbols on the schematics (Paxinos and Watson, 1997) represent the most ventral point of the infusion cannula tracts for rats that received bilateral microinfusions into the NAC for experiment 1 (saline/home cage: closed squares; saline/heroin-paired context: open squares; AP-5/home cage, closed triangles; AP-5/heroin-paired context, open triangles; CNQX/home cage, closed circles; $\mathrm{CNQX}$ /heroin-paired context, open circles). For experiment 2, symbols represent the most ventral point of the infusion tract for rats receiving unilateral microinfusions into the BLA plus the contralateral NAC (home cage, closed circles; heroin-paired context, open circles) or the ipsilateral NAC (home cage, closed triangles; heroin-paired context, open triangles), or a control microinfusion of saline into the BLA and NAC (home cage, closed squares; heroin-paired context: open squares). Numbers indicate the distance from bregma in millimeters. 

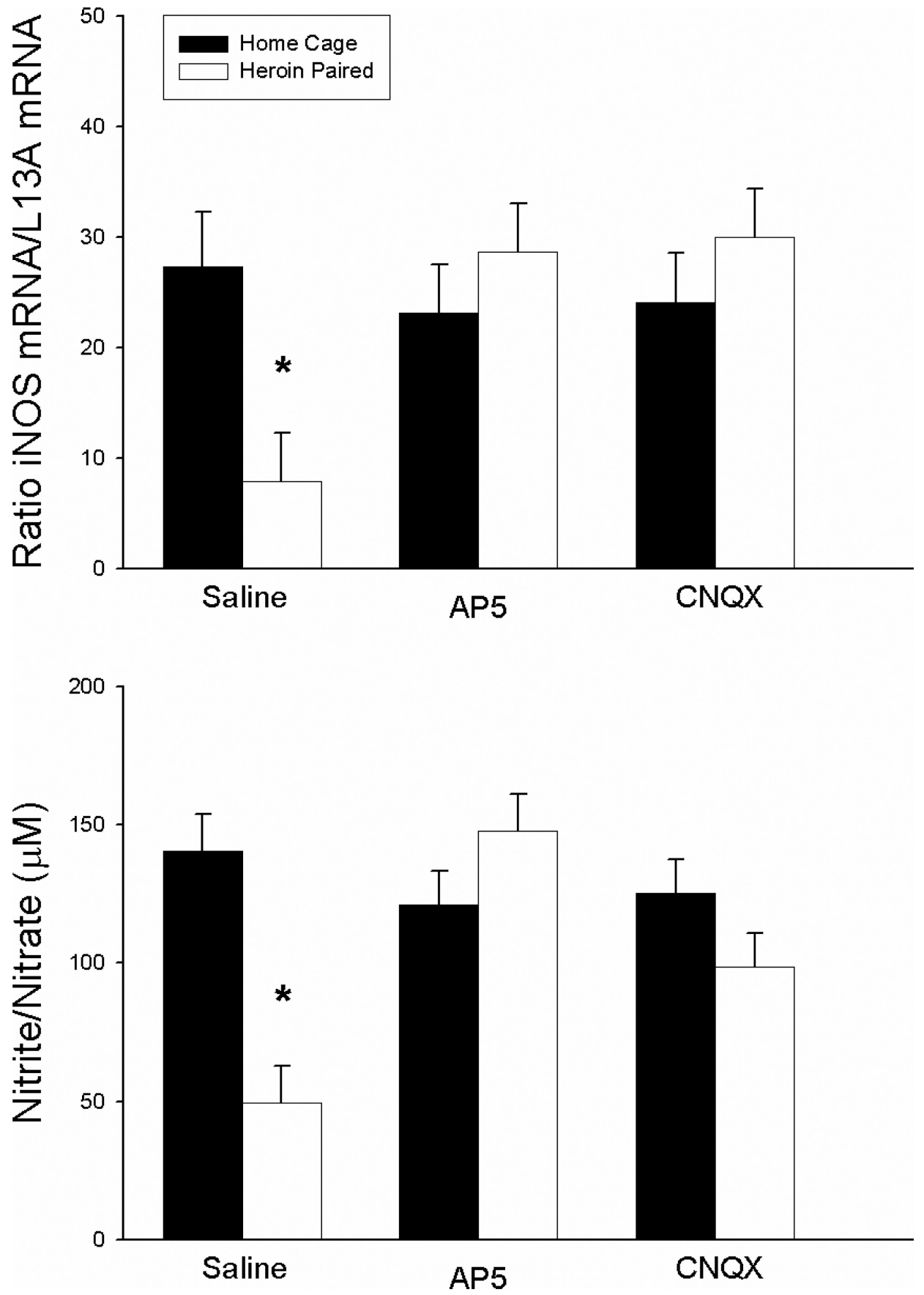

Figure 2.

Effect of antagonist treatment and context on LPS-induced expression of iNOS mRNA in the spleen as determined by real-time RT-PCR (top panel) and nitrite/nitrate production in the serum as determined by the Greiss reagent assay (bottom panel). Exposure to the previously heroin-paired context (Saline, white bar) resulted in conditioned suppression of iNOS mRNA levels in the spleen and a conditioned suppression of the byproducts of nitric oxide production in the serum as compared to the home cage control group (Saline, black bar). Intra-NAC microinfusion of NMDA or AMPA/kainate receptor antagonist blocked the effect of the conditioned stimulus (AP5/CNQX, white bar). Real-time RT-PCR data are expressed as iNOS copy number per 10 ng cDNA based on a standard curve using Roche 
LightCycler software. Nitrite/nitrate data are expressed as the micromolar concentration of nitrite/nitrate. 

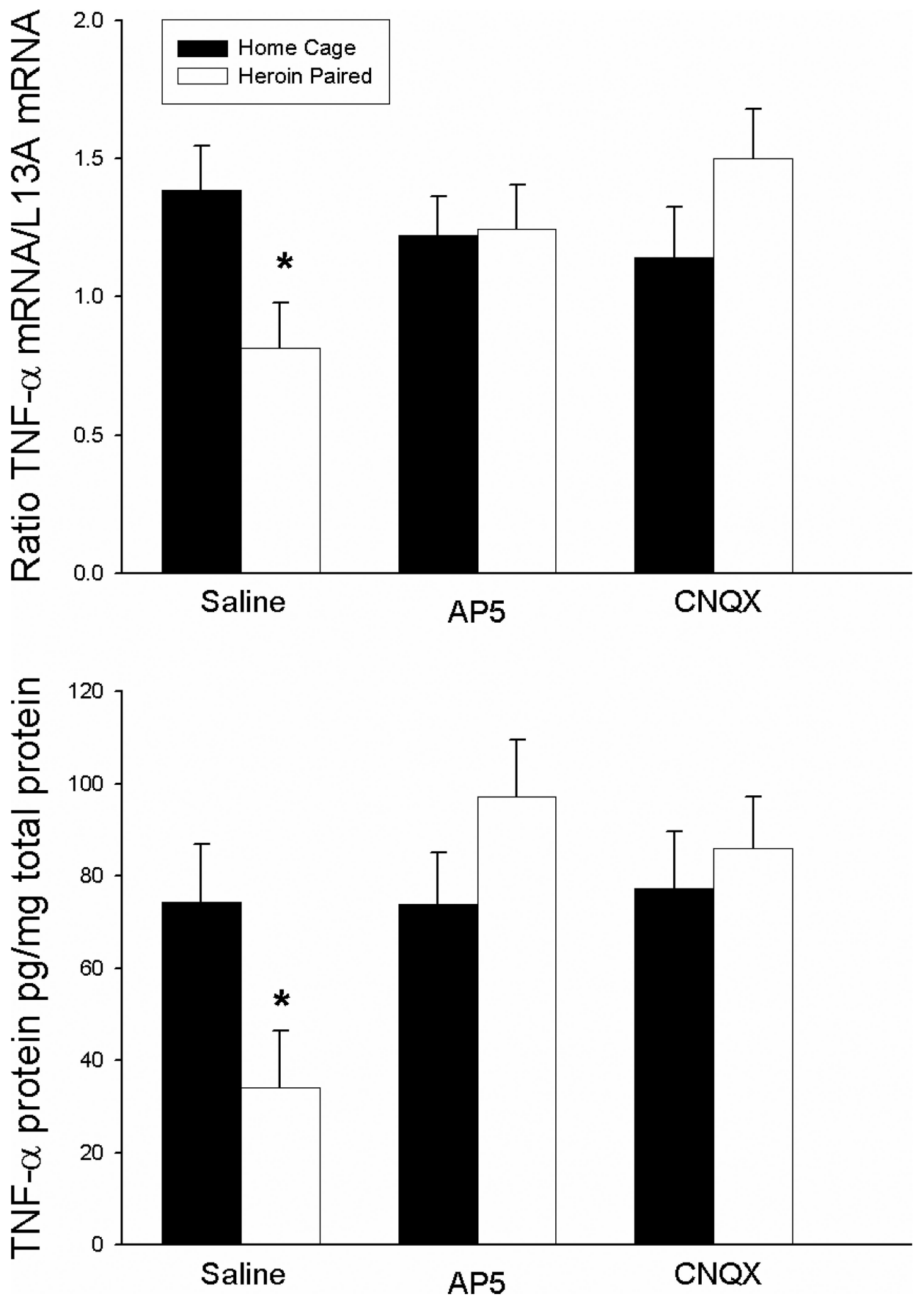

Figure 3.

Effect of antagonist treatment and context on LPS-induced expression of TNF-a mRNA in the spleen as determined by real-time RT-PCR (top panel) and TNF-a protein levels as determined by ELISA (bottom panel). Exposure to the previously heroin-paired context (Saline, white bar) resulted in a conditioned suppression of TNF-a mRNA and protein levels in the spleen as compared to the home cage control group (Saline, black bar). IntraNAC microinfusion of NMDA or AMPA/kainate receptor antagonist blocked the effect of the conditioned stimulus (AP5/CNQX, white bar). Real-time RT-PCR data are expressed as TNF-a copy number per 10 ng cDNA based on a standard curve using Roche LightCycler software. ELISA data are expressed as pg of TNF-a protein per mg of total protein. 

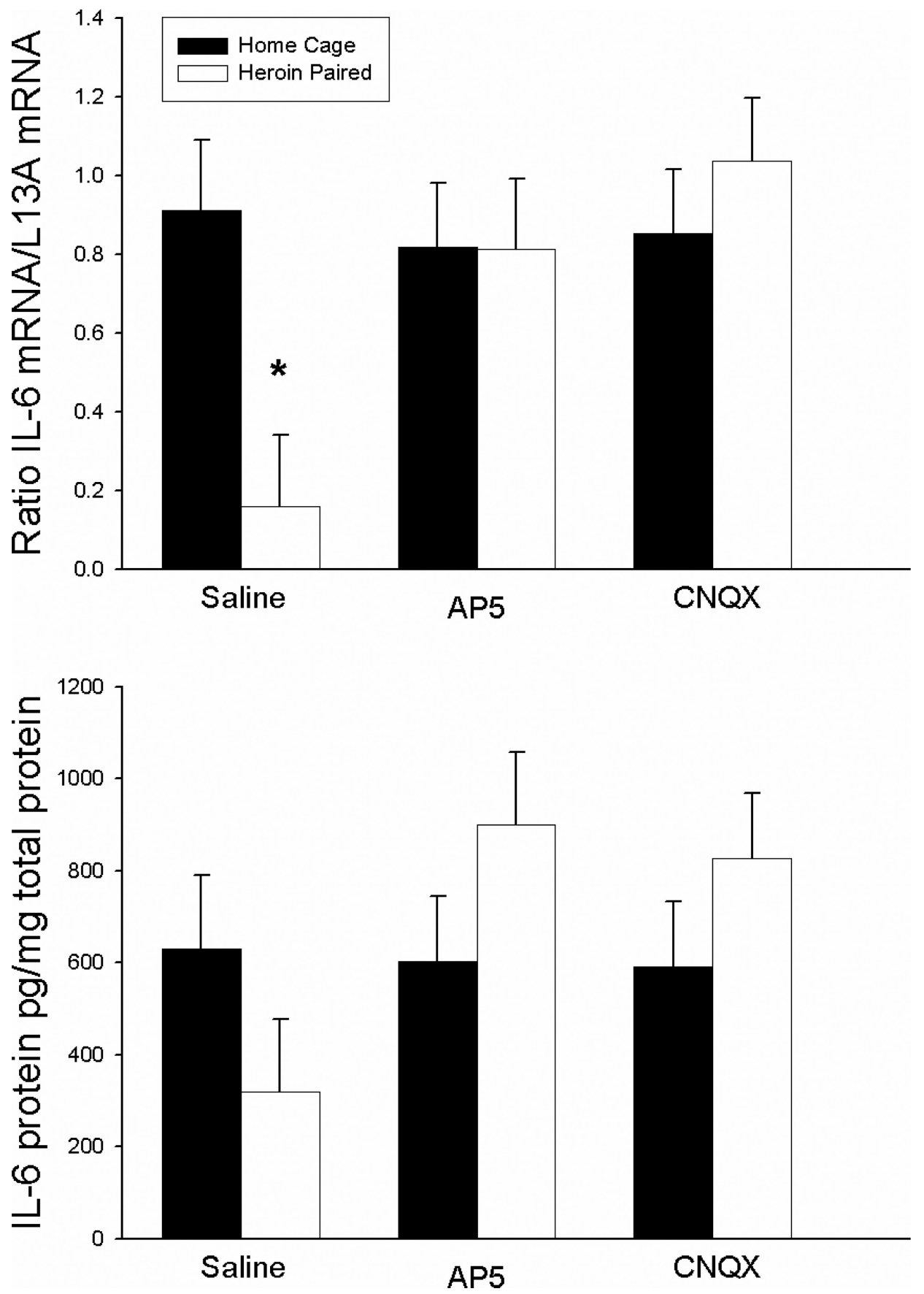

Figure 4.

Effect of antagonist treatment and context on LPS-induced expression of IL-6 mRNA in the spleen as determined by real-time RT-PCR (top panel) and IL-6 protein in the spleen as determined by ELISA (bottom panel). Exposure to the previously heroin-paired context (Saline, white bar) resulted in a conditioned suppression of IL-6 mRNA levels in the spleen as compared to the home cage control group (Saline, black bar). Intra-NAC microinfusion of NMDA or AMPA/kainate receptor antagonist blocked the effect of the conditioned stimulus (AP5/CNQX, white bar). Real-time RT-PCR data are expressed as iNOS copy number per 10 ng cDNA based on a standard curve using Roche LightCycler software. ELISA data are expressed as pg of IL-6 protein per mg of total protein. 

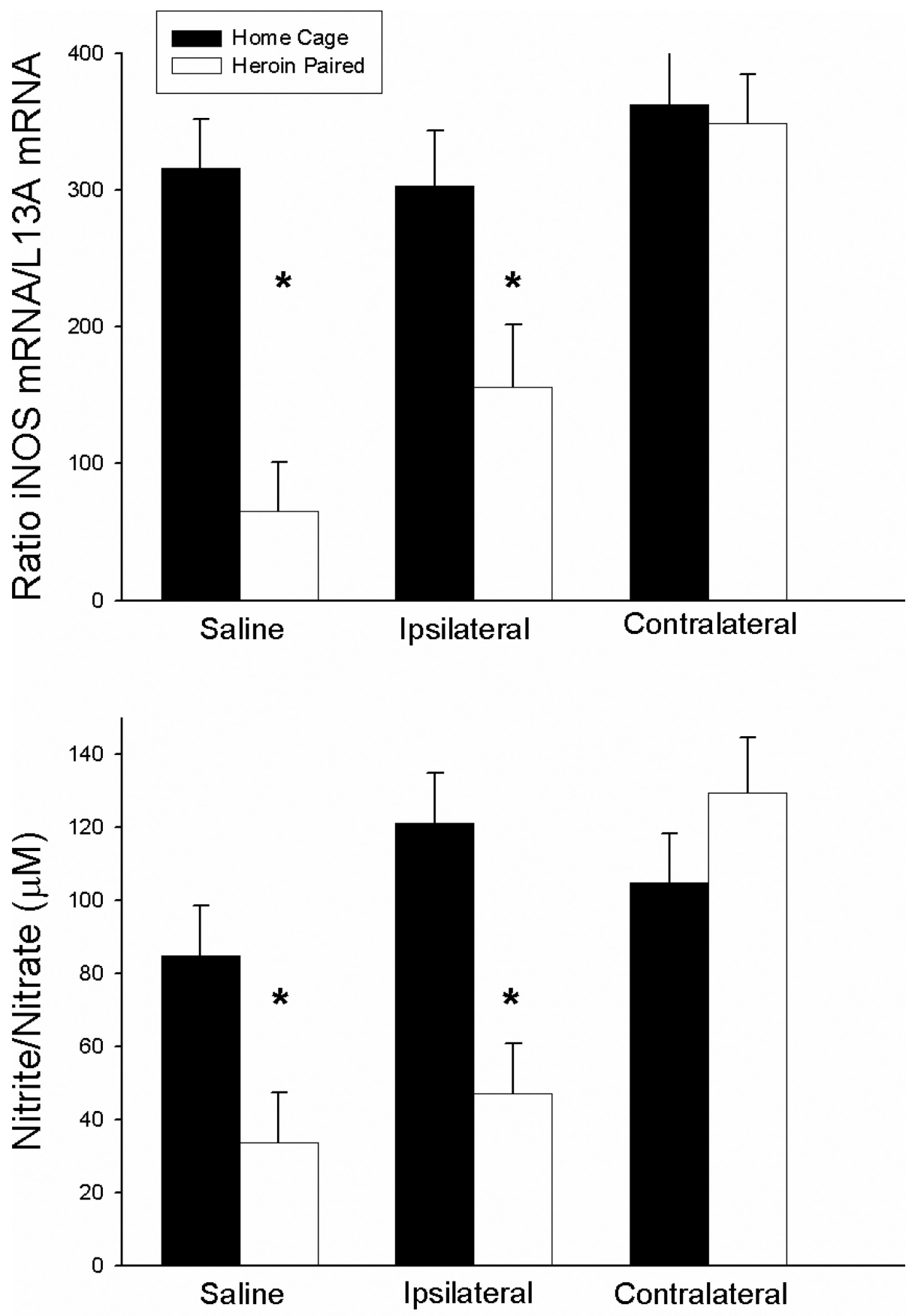

Figure 5.

Effect of antagonist treatment and context on LPS-induced expression of iNOS mRNA in the spleen as determined by real-time RT-PCR (top panel) and nitrite/nitrate production in the serum as determined by the Greiss reagent assay (bottom panel). Exposure to the previously heroin-paired context (Saline, white bar) resulted in a conditioned suppression of iNOS mRNA levels in the spleen and a conditioned suppression of the byproducts of nitric oxide production in the serum as compared to the home cage control group (Saline, black bar). Disconnection of the VTA-BLA-NAC circuit blocked the effect of the conditioned stimulus (Contralateral, white bar). Ipsilateral administration of intra-NAC AP5 and intraBLA SCH23390 did not alter the conditioned suppression (Ipsilateral, white bar). Real-time 
RT-PCR data are expressed as iNOS copy number per $10 \mathrm{ng}$ cDNA based on a standard curve using Roche LightCycler software. Nitrite/nitrate data are expressed as the micromolar concentration of nitrite/nitrate. 

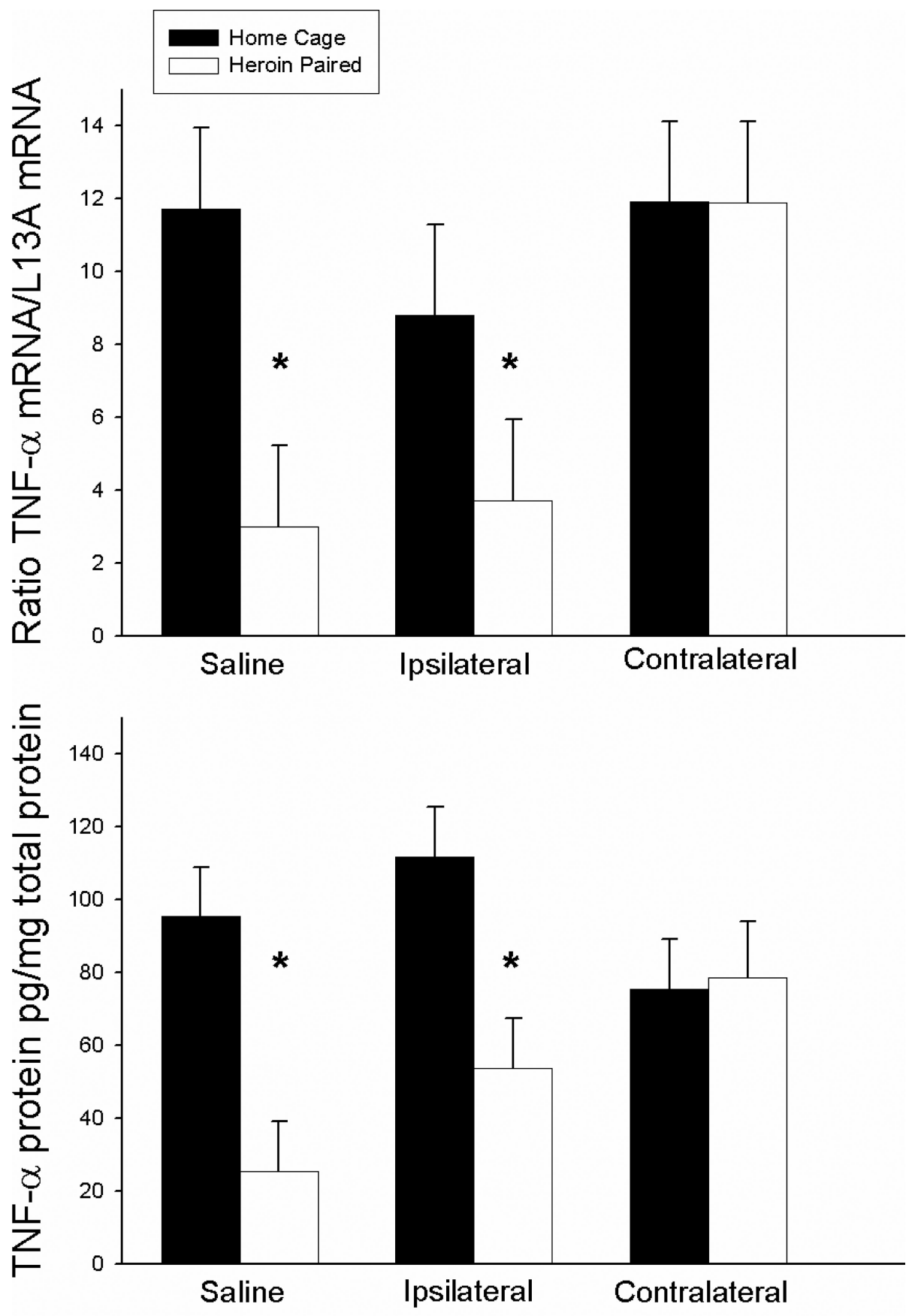

Figure 6.

Effect of antagonist treatment and context on LPS-induced expression of TNF-a mRNA in the spleen as determined by real-time RT-PCR (top panel) and TNF-a protein levels as determined by ELISA (bottom panel). Exposure to the previously heroin-paired context (Saline, white bar) resulted in a conditioned suppression of TNF-a mRNA and protein levels in the spleen as compared to the home cage control group (Saline, black bar). Disconnection of the VTA-BLA-NAC circuit blocked the effect of the conditioned stimulus (Contralateral, white bar). Ipsilateral administration of intra-NAC AP5 and intra-BLA $\mathrm{SCH} 23390$ did not alter the conditioned suppression of TNF-a (Ipsilateral, white bar). Realtime RT-PCR data are expressed as TNF-a copy number per $10 \mathrm{ng}$ cDNA based on a 
standard curve using Roche LightCycler software. ELISA data are expressed as pg of TNFa protein per $\mathrm{mg}$ of total protein. 

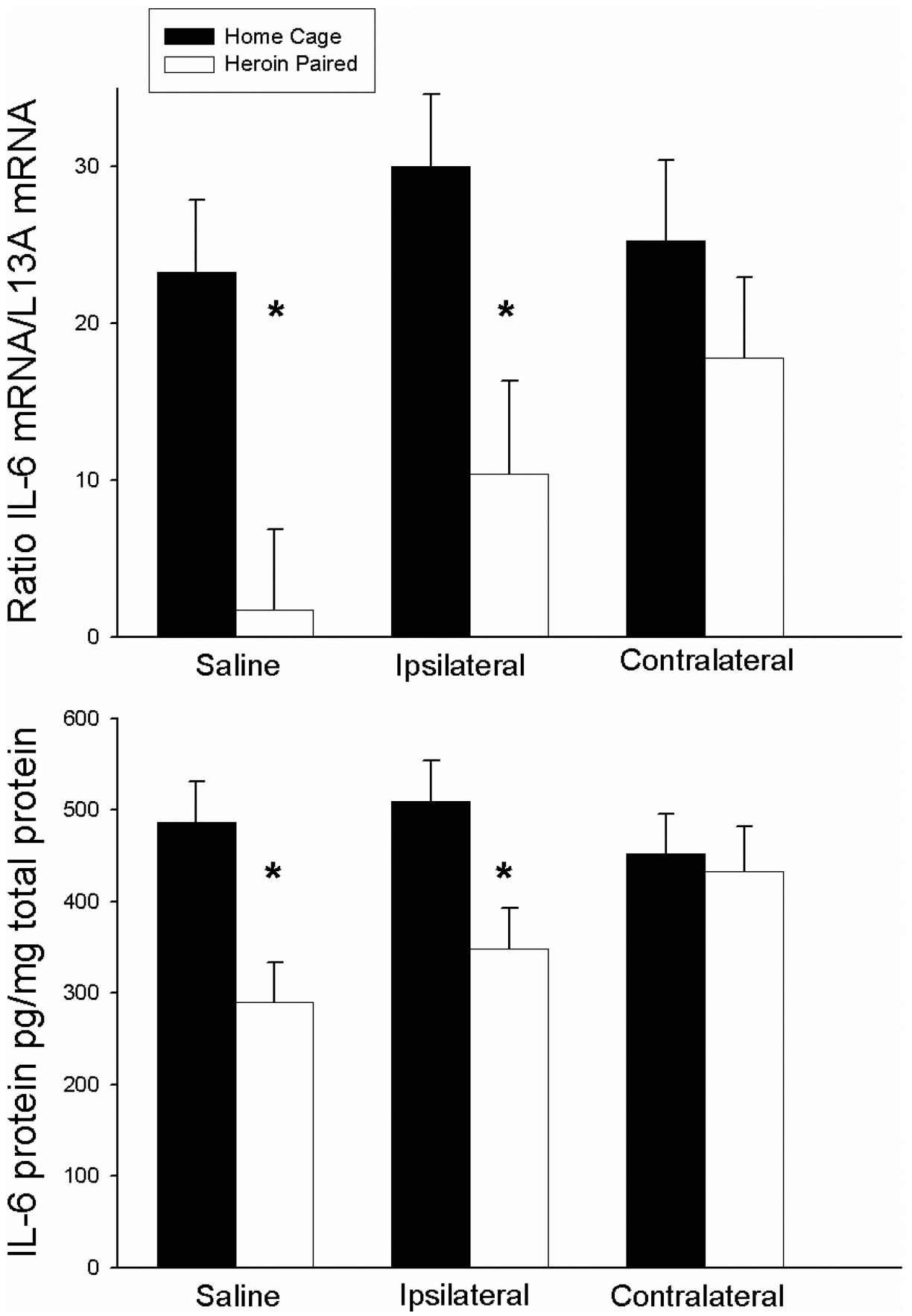

Figure 7.

Effect of antagonist treatment and context on LPS-induced expression of IL-6 mRNA in the spleen as determined by real-time RT-PCR (top panel) and IL-6 protein in the spleen as determined by ELISA (bottom panel). Exposure to the previously heroin-paired context (Saline, white bar) resulted in a conditioned suppression of IL-6 mRNA and protein levels in the spleen as compared to the home cage control group (Saline, black bar). Disconnection of the VTA-BLA-NAC circuit blocked the effect of the conditioned stimulus (Contralateral, white bar). Ipsilateral administration of intra-NAC AP5 and intra-BLA SCH23390 did not alter the conditioned suppression of IL-6 (Ipsilateral, white bar). Real-time RT-PCR data are expressed as IL-6 copy number per 10 ng cDNA based on a standard curve using Roche 
LightCycler software. ELISA data are expressed as pg of IL-6 protein per mg of total protein. 